ENTREVISTA

INTERVIEW

\title{
Nascendo no Brasil, uma entrevista com Maria do Carmo Leal
}

\author{
Borning in Brazil, an interview with \\ Maria do Carmo Leal \\ Naciendo en Brasil, una entrevista con \\ Maria do Carmo Leal
}

doi: 10.1590/0102-311X00105018

\section{Marilia Sá Carvalho ${ }^{1}$ \\ Maria do Carmo Leal 2 \\ Luciana Dias de Lima ${ }^{2}$}

\footnotetext{
1 Programa de Computação Científica, Fundação Oswaldo Cruz, Rio de Janeiro, Brasil.

2 Escola Nacional de Saúde Pública

Sergio Arouca, Fundação Oswaldo Cruz,

Rio de Janeiro, Brasil.

Correspondência

M. S. Carvalho

Programa de Computação Científica,

Fundação Oswaldo Cruz.

Av. Brasil 4365, Rio de Janeiro, $R J$

21040-360, Brasil.

mariliasaca@gmail.com
}

Entrevista com a professora Maria do Carmo Leal, docente do Departamento de Epidemiologia e Métodos Quantitativos, Escola Nacional de Saúde Pública Sergio Arouca, Fundação Oswaldo Cruz.

Maria do Carmo Leal, conhecida por colegas e alunos como Duca, coordenou a pesquisa Nascer nas Prisões, cujos dados foram utilizados na argumentação a favor do habeas corpus coletivo para que as grávidas e mulheres que têm filhos até 12 anos fiquem em prisão domiciliar. Vitória importante dos direitos humanos. Antes disso, Duca coordenou a pesquisa nacional sobre "Nascer no Brasil", cujos resultados vêm sendo trabalhados por diversos setores, seu grupo inclusive, para fazer do parto uma experiência positiva, sob o controle das próprias mulheres. É a pesquisa epidemiológica voltada para a intervenção na Saúde Coletiva. Por isso, esta entrevista. 


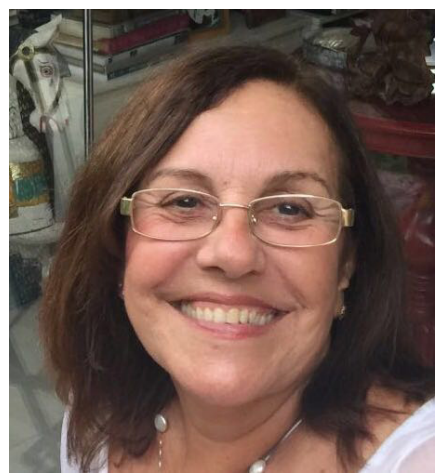

Maria do Carmo Leal (pesquisadora da Escola Nacional de Saúde Pública Sergio Arouca, Fundação Oswaldo Cruz).

Marilia Duca, queríamos começar perguntando por que e como você escolheu seus temas de pesquisa, e como é a sua história neste tema, saúde da mulher e da criança?

Duca Eu comecei o meu trabalho como pesquisadora em Saúde Pública estudando hipertensão arterial, um problema do adulto, e trabalhei com esta questão no meu Mestrado em 1980. Eu já tinha alguma formação em epidemiologia lá na Universidade Federal da Bahia (UFBA), trabalhando com Sebastião Loureiro. Inclusive o meu primeiro inquérito, lá na Bahia, foi com um grupo de mulheres muito marginalizado, as prostitutas do Pelourinho, na época em que o governo estava fazendo a remoção delas daquela área para recuperar a parte histórica de Salvador para o turismo.

Quando cheguei na Escola Nacional de Saúde Pública Sergio Arouca, Fundação Oswaldo Cruz (ENSP/Fiocruz) recém-formada, para fazer o curso de Saúde Pública, um curso revolucionário àquela época, fui chamada para fazer parte da equipe do 1o inquérito populacional sobre hipertensão arterial, no Rio Grande do Sul. Foi um inquérito muito bem feito, eu aprendi muito. Um tempo depois, apareceu a oportunidade de participar do Programa Ampliado de Imunizações (PAI) e me envolvi muito com os programas de imunização, com as campanhas de vacinação. Na época havia uma discussão na esquerda e dentro da ENSP, que não seria correto apoiar as campanhas de vacinação, pois elas significavam um investimento pontual, em uma necessidade específica de saúde, mas não resolveria o problema fundamental que era a necessidade de uma atenção integral, com investimento em serviços rotineiros de saúde, na atenção primária, com integração com outros níveis de cuidado. Estávamos no início dos anos 1980, ainda na ditadura militar.

Marilia Pois é, se acreditava que havia uma contradição entre uma coisa e outra.

Duca E foi sofrido pra mim, pois quando eu via aquela discussão, eu pensava: "não está certo, vamos ter de apoiar essa inciativa e participar". Porque sarampo ainda matava muito nos anos 1980 e eu pensava que se não podemos fazer tudo era importante fazer o que fosse possível para prevenir mortes infantis. Então entramos nessa frente e você, Marilia, também entrou.

Em 1984, fiz um projeto de pesquisa para estudar a etiologia das diarreias, que à época era causa muito importante de óbito infantil. Esse estudo foi financiado pela Organização Pan-Americana da Saúde (OPAS), e com este recurso conseguimos comprar um dos primeiros microcomputadores da nossa escola, pois não havia por aqui. Nessa época comecei nessas questões na saúde da criança e depois fui estudar a mortalidade infantil. Fizemos, Paulo Sabroza e eu, um projeto para a Empresa Brasileira de Inovação e Pesquisa (Finep) no final dos anos 1980 sobre a mortalidade infantil na Região Metropolitana do Rio de Janeiro. Depois, eu fui estudando a mortalidade infantil, me envolvendo com a análise da qualidade dos dados nos sistemas de informação, junto com a Célia Landmann Szwarcwald, minha companheira em muitos estudos.

Nessa época eu era da comissão de epidemiologia da Associação Brasileira de Saúde Coletiva (Abrasco), fui muitos anos, acho que uns 15 anos. Montamos os primeiros congressos, planos direto- 
res da epidemiologia no Brasil e os cursos de formação para os serviços de saúde com as instituições de ensino. Primeiro foram os cursos de especialização, depois os mestrados profissionais.

Como pesquisadora, meu envolvimento foi cada vez maior com a mortalidade infantil, que aos poucos foi se tornando neonatal e se aproximando do momento do parto. Atualmente, $52 \%$ dos óbitos ocorrem na primeira semana de vida, mas destes, a metade no primeiro dia após o nascimento, ou seja, em torno do parto. Fui amadurecendo a necessidade de estudar o parto e o nascimento. Fomos verificando também que eram poucos os grupos de pesquisa trabalhando nesse campo com uma visão de saúde pública. Se na área da criança tínhamos muitos e excelentes grupos, como os grupos das coortes de Pelotas, Ribeirão Preto e Maranhão, dentre outros, na área da mulher somente o grupo da Universidade Estadual de Campinas (Unicamp) tinha estudos de grande porte. Na nossa cronologia, estávamos já em meados da década de 2000.

Marilia A maioria dos estudos com a mulher era somente relacionado à saúde da criança.

Duca Era uma forma nossa de enxergar a mulher apenas como mãe. Nós fomos descobrindo aos poucos que quando entramos para estudar a mortalidade da criança, em torno do parto, estávamos sem ver a mulher, víamos apenas a gestante. Se a criança está morrendo quando nasce, provavelmente a mulher também está morrendo, por problemas comuns.

A mulher fica esquecida, ou foi relegada, digo, até por nós mesmos, nosso grupo de pesquisa. Mas fomos aos poucos tomando o partido da mulher e atualmente publicamos mais com temas da mulher do que da criança, porque é uma área pouco trabalhada, quase abandonada e que temos de olhar com muita atenção, porque esta sociedade não vai melhorar enquanto não diminuir o desinteresse pela mulher, que é uma expressão do machismo que nos constitui.

Acho que essa questão do machismo nos arruína como sociedade, que combinado com a convivência acrítica com essa desigualdade social enorme que temos, faz de nós uma sociedade perversa. Se acrescermos a isso o racismo, a intolerância com as diferenças étnicas... Não somente a população negra, os indígenas também. São questões gravíssimas que a gente tem.

Nosso primeiro projeto sobre a mortalidade perinatal, com ênfase na atenção ao parto, foi em cooperação com a Secretaria Municipal de Saúde do Rio de Janeiro. Esse projeto, de âmbito municipal, foi o protótipo, o laboratório pra o Nascer no Brasil. No nosso próximo inquérito sobre parto e nascimento, o Nascer no Brasil II, nós vamos introduzir a temática do aborto.

Marilia Antes de chegar aí, a gente tinha algumas questões. Por exemplo, você está falando de desigualdades, o que você tem a dizer sobre as desigualdades regionais no Brasil? Porque, se bem me lembro, era brutal a diferença da mortalidade infantil. Lembro da época em que analisei isso, há muitos anos atrás, eram 200 por mil, um absurdo, no interior do Ceará, e o Rio de Janeiro estava em 60 por mil nascidos vivos.

Luciana Mas agora mudou.

Duca Mudou muito, e o que aconteceu nesses últimos 15 a 20 anos é que as diferenças regionais diminuíram bastante na mortalidade infantil. A mortalidade infantil no Brasil está em torno de 13 por mil nascidos vivos, no Rio de Janeiro está em 12 e nos estados do Nordeste 17, não muito acima. Quando comparada à de países desenvolvidos, temos 4 a 5 vezes mais óbitos.

E a mortalidade materna? Esse é um problema porque creio que esse indicador no Brasil é muito pior do que o da mortalidade infantil. O que tem a ver com a falta de valor, discriminação, com a falta de lugar para a mulher na sociedade, que termina por não cuidar dela da forma adequada. Cuidou-se muito mais da criança, fez-se um investimento grande para reduzir a mortalidade infantil e se obteve sucesso. Como visto, diminuiu muito a diferença entre as regiões e também entre os grupos sociais, mas na mortalidade materna nós temos um padrão que, se por um lado reflete também as diferenças regionais (variando entre 40 e 70 óbitos por 100 mil nascidos vivos entre as regiões mais ricas e mais pobres) e entre os grupos sociais, por outro, nos coloca em uma situação muito desconfortável, quando comparada à dos países desenvolvidos. Eles têm esse indicador 6 a 10 vezes menor que o nosso. Aliás, se considerarmos os estados do Brasil separadamente, em alguns nós temos valores mais elevados que 100 óbitos por 100 mil nascidos vivos, muito acima da média nacional que é de 60 .

Marilia E nesses 60 do Brasil, acho que há problema de estimação, porque nós não temos dados de boa qualidade nessa área não.

Luciana Eu estava lendo que há uma queda na mortalidade materna... 
Duca Também houve uma melhora na notificação da mortalidade materna. Em anos mais recentes, a investigação de óbitos de mulheres em idade fértil ampliou muito, aliás, um trabalho que foi inicialmente conduzido pela Célia Landmann Szwarcwald, sob a forma de uma pesquisa. Muitos óbitos que não são considerados óbito materno, são, de fato. Então, todos, 100\% dos óbitos ocorridos em mulheres em idade fértil começaram a ser investigados, inclusive no Rio de Janeiro, e em mais outros estados. Não temos essa cobertura na investigação para todo o Brasil, mas atualmente entre 70\%-80\% desses óbitos estão sendo investigados. Isso melhorou o registro, de forma que a não queda também tem a ver, em parte, com a melhora do registro. Entretanto, não há explicação aceitável para a mortalidade materna ser tão alta. Recentemente, escrevemos um artigo para a Enciclopédia de Saúde Pública da Oxford, que o Paulo Buss coordenou para a região da América Latina, e nos surpreendemos com os dados de Cuba: tem a menor mortalidade infantil da América, igual à do Canadá, de 6 por mil nascidos vivos, mais baixa que a dos Estados Unidos, porém, tem uma taxa de mortalidade materna alta, de 30. Pra confirmar a minha hipótese da desvalorização da mulher latino-americana.

Isso é um dado radical, o óbito materno, mas eu estou ressaltando que o machismo da nossa sociedade latino-americana tem a ver com isso, com a desvalorização e falta de cuidado com a mulher, dado que a maioria dessas mortes é evitável.

Marilia E a proibição do aborto?

Duca É a quarta causa da mortalidade materna no Brasil, é uma causa expressiva. Isso porque não é tudo investigado, eu suponho que seja maior. O aborto como causa de morte deve estar subnotificado porque é crime. As mulheres omitem.

Marilia A primeira causa de mortalidade materna é?

Duca Hipertensão, hemorragias, infecções e aborto. Praticamente tudo é evitável. Nos países desenvolvidos predominam causas menos ou mesmo não evitáveis, mortes ligadas a doenças que a mulher traz. Por exemplo, lupus, doenças autoimunes, que são complicadas. Então, a maioria é causa indireta de morte, não é causa direta. No nosso caso, quase tudo é causa direta, que se bem tratadas num pré-natal adequado e/ou com uma boa atenção no parto, as mulheres não morreriam.

O pré-natal é fundamental para todos os resultados obstétricos e perinatais, mas o momento do parto tem grande importância. Já é conhecido o papel fundamental que têm as três demoras no atendimento ao parto para complicações obstétricas graves e o óbito materno: a primeira relacionada à percepção do problema pela gestante, que vai ser tanto mais precoce quanto mais informada ela for; a segunda, diz respeito à demora em chegar ao serviço de saúde; e a última, a demora para ser atendida adequadamente depois que chega ao serviço de saúde. Todas elas, como podem imaginar, aumentam em mulheres com piores condições sociais e que vivem em lugares sem uma boa assistência ao parto. São casos dramáticos, por exemplo, de um sangramento cuja demora na percepção da gravidade, no atendimento e na efetividade do tratamento é fatal. O mais incrível no Brasil é que a elevadíssima taxa de mortalidade materna convive com $99 \%$ dos partos ocorrendo dentro de um hospital. Não era para estar assim, pois, de alguma forma, o acesso está garantido para todas.

Marilia Fale-me um pouco sobre parto no hospital e fora dele, esses movimentos que estão acontecendo agora de doulas, enfermeiras obstétricas.

Duca Isso é uma coisa bem interessante que está acontecendo no Brasil. Temos dois tipos de resultado para o parto domiciliar: se ele ocorre no interior do Norte e Nordeste, em áreas de municípios muito pobres, onde a subnotificação do óbito infantil é grande, o parto domiciliar é associado à maior mortalidade ao nascer. Nós visitamos esses municípios de alta subnotificação de óbitos infantis, cuja taxa de mortalidade infantil não era compatível com as condições sociais dos lugares, para fazer busca ativa de óbitos em 2008. Íamos ao cemitério, falávamos com as pessoas da comunidade e por meio destas informações identificamos as mães de recém-nascidos mortos e não notificados tanto como óbito quanto como nascidos vivos. Fazíamos então uma avaliação nos domicílios desses municípios, onde encontramos muitos partos domiciliares, que nessas áreas, se associam à mortalidade infantil. Família em extrema pobreza, cujas mulheres são atendidas por parteiras que não têm formação e sem serviços de saúde de apoio por perto.

Distante, muito distante, do que ocorre nesses municípios pobres está o parto domiciliar nas capitais das regiões Sudeste e Sul. O nascimento domiciliar numa cidade como o Rio de Janeiro, São Paulo, Belo Horizonte, que algumas mulheres da classe média hoje optam por fazer, é realizado por enfermeiras obstétricas competentes para este atendimento e não vem representando risco para a 
saúde materna e do bebê. Ao contrário, são relatados como experiências de grande realização pessoal e familiar para as mulheres que o vivenciaram. Então, tudo no Brasil que você for trabalhar com parto tem duas versões, uma que é negativa e outra que é um bom indicativo.

Eu queria contar uma experiência que tive como pesquisadora naquele estudo caso-controle que acoplamos ao estudo da busca ativa de óbitos. Essa pesquisa foi muito difícil pra mim, porque pela primeira vez tive de devolver uma quantidade expressiva de recursos ao órgão financiador por ocasião da prestação de contas. Tivemos de colocar combustível, óleo diesel, nas embarcações emprestadas pelas secretarias de saúde dos municípios para chegar aos domicílios dessas mulheres em áreas remotas na Região Norte, onde não havia outra forma de acesso. Algumas vezes a equipe viajava 12 horas para alcançar um lugarejo. No Nordeste, em áreas de difícil acesso, íamos de motocicleta, com moto-táxis, alugamos jegues quando não havia motocicleta e, claro, os recibos eram em papel de pão, ou do que havia no lugar. A insensibilidade dos órgãos de fomento com o pesquisador numa situação dessas é algo inacreditável. Tive de devolver em dinheiro o que não foi aceito como prestação de contas nem mesmo do combustível, cujos recibos estavam dentro do padrão oficial.

Marilia Contextos totalmente diferentes.

Duca Sobre o risco do parto domiciliar existe um estudo clássico feito na Inglaterra, denominado Birth Place, de 2014, que mostrou que, no contexto inglês, não há problema para a mulher e isto fica por conta da sua decisão e escolha. O estudo mostrou um risco ligeiramente aumentado para as primíparas, mas um estudo posterior comprovou que isto foi devido à qualificação inadequada das midwives nas áreas onde o problema ocorreu. Na multípara nenhuma diferença nos resultados para a mãe e o bebê quando a atenção era domiciliar ou hospitalar. É preciso dizer que os problemas com as gestantes são adequadamente identificados durante o pré-natal, que na Inglaterra também é feito pelas midwives. Quando há problemas de saúde e as gestantes são classificadas como de risco, elas são encaminhadas ao obstetra.

Sobre a questão das doulas, que vocês haviam comentado, as pessoas confundem muito dizendo que elas fazem parto. Doulas não fazem parto, dão suporte físico e emocional, como orientar posições, respiração, ajudar no empoderamento da mulher. E fazem muito bem para a parturiente. Há, às vezes, uma grande confusão com esses papéis porque estamos vivendo uma mudança no modelo de atenção ao parto, com novos atores, com resistências por parte dos atores anteriores e isto sempre causa um estranhamento no início.

As doulas fazem um curso curto e adquirem noção de trabalho de parto e de complicações. Geralmente é uma mulher envolvida com essa questão, que quer ajudar as outras a terem um bom parto. Na maioria das vezes essa decisão de ser doula veio da própria experiência com um parto anterior.

Nós tivemos alguns problemas com a entrada da doula no serviço público. Às vezes, as doulas cobram pelos serviços no setor privado e isto está dentro do esperado. A gestante resolveu contratar uma doula, e tudo bem. Mas dentro do serviço público, nada pode ser cobrado. Então, houve enfrentamentos em algumas maternidades. E apareceu como proibição, mas, na verdade, a questão era a cobrança, não a doula. Agora as coisas estão mais calmas e são experiências interessantes que estamos vivendo no Brasil. A literatura também mostra que a presença da doula é boa para a mulher que está em trabalho de parto.

Marilia Deixa eu fazer uma ponte agora. Como você leva essas coisas que você está nos contando para enfrentar o problema da Saúde Pública no país? Umas das discussões atuais da epidemiologia é o retorno do foco para a intervenção, para a saúde pública. Eu acho que você tem uma grande experiência nesse sentido. Conta para a gente.

Duca É mesmo, isso tem a ver, como eu disse no início, com essa coisa da Saúde Pública e a epidemiologia aqui no Brasil ter sido sempre muito misturada com os serviços de saúde, gerando um compromisso mútuo muito grande. A própria Abrasco, que é a nossa associação, é também a associação dos profissionais de saúde pública dos serviços de saúde. Associações, por exemplo, de epidemiologia, são associações de cientistas em outros países. Aqui não, a nossa é miscigenada, no bom sentido, ela incluiu o pessoal do serviço, o sanitarista. Temos esse compromisso de que as pesquisas não podem morrer com a publicação e nem com a realização de teses dos alunos. O compromisso é também de devolver para a sociedade, para os serviços de saúde, para os profissionais. E isso é uma coisa muito forte dentro do nosso grupo de pesquisa. Então, quando a gente viu essa situação tão ruim da assistência ao parto e ao nascimento, nos posicionamos com a intenção de participar do movimento de mudança. 
O contato com as experiências de atenção ao parto em países desenvolvidos e toda a discussão sobre a necessidade de reforçar a autonomia da mulher para que ela possa ter o parto que ela quiser, fizeram toda a diferença para o nosso grupo de pesquisa, que é também de militância pela causa da maternidade feliz e autônoma. Digo mesmo que eu voltei muito injuriada com a nossa situação no Brasil depois que eu vi como são tratadas as gestantes e como nascem as crianças nesses países, comparando com o que nós fazemos aqui.

Marilia Estamos muito distantes dessa realidade?

Duca Muito distantes. Em Londres eu fui num hospital universitário que tem a área da maternidade quase toda ocupada pelas midwives. E o que as separa da área obstétrica é uma porta. A maioria dos quartos não tem aspecto de hospital, com equipamentos embutidos na parede, parece um quarto de casa. Mas, se necessário, está tudo ali. E o companheiro dela, ou quem ela escolher para acompanhante, fica com ela, isto é assegurado. Tem banheiras, mas nem todas as mulheres desejam ter os filhos dentro d'água, embora possam se quiserem. A área para deambulação durante o trabalho de parto é muito ampla, cheia de plantas, climatizada para ter plantas o ano todo e com música suave, relaxante. A música ajuda as mulheres a se acalmarem e esse espaço tão agradável e silencioso permite o contato com elas mesmas, com seus bebês.

É um grande contraste com o que se vê por aqui, com as nossas mulheres pobres. O sistema de saúde inglês atende a todos, as mulheres que vi eram pessoas simples, mas estavam muito bem tratadas. Eu tive uma plena lição de cidadania, o que é receber uma criança, um cidadão inglês. Aqui não, as mulheres são maltratadas, gritaria, sofrimento, falta de espaço físico e de atenção. A luta das midwives é pelo cuidado uma a uma, ou seja, para cada mulher uma midwife, cuidado em tempo integral e dedicação exclusiva. Há também uma grande luta das midwives contra o excesso de trabalho burocrático, gastando muito tempo para anotar todos os procedimentos por causa dos processos que ocorrem, a judicialização da saúde.

Marilia Mas isso está sendo geral, uma das crises do National Health Services (NHS) é que toda a burocracia passou a ser dos médicos em nome de "vamos economizar". Então, você economiza secretárias para o registro e bota o peso nas costas de quem devia estar principalmente assistindo a população.

Luciana Nossas enfermeiras também estão muito sobrecarregadas.

Duca Isso também ocorre aqui, em maior intensidade, eu acho. Mas as midwives inglesas também lutaram para alcançar esse lugar que têm na assistência ao parto. Elas foram muito importantes para espalhar para o mundo esse modelo de atenção ao parto menos intervencionista e focado na mulher. Eu as conheci num congresso chamado Normal Labor and Birth Conference (https://normalbirthcon ference.com/), em 2011, quando eu fui pela primeira vez. Gostei muito e tive a surpresa da pequena presença de médicos obstetras e pediatras, quase todos os participantes eram midwives. Acho que tem uma certa separação entre eles lá também. Mas funcionam de uma forma respeitosa, são parceiros, têm um compartilhamento de trabalho que se expressa nessas ocasiões. Nós não tínhamos isso aqui, mas acho que agora estamos dando passos nessa direção. No XXII Congresso Mundial de Ginecologia e Obstetrícia (FIGO 2018) que acontecerá no Brasil este ano, a direção da Associação Brasileira de Obstetrizes e Enfermeiros Obstetras (ABENFO), irá para a mesa de abertura. Estamos começando a dar passos importantes de civilidade e companheirismo.

Marilia Voltando à pergunta que fizemos, conte sua experiência na intervenção, para mudar essa realidade de fato.

Duca Fizemos muitas coisas. A primeira, junto com a publicação dos resultados desse estudo nos Cadernos de Saúde Pública 1 foi o lançamento de um Sumário Executivo (http://www.ensp.fiocruz. br/portal-ensp/informe/site/arquivos/anexos/nascerweb.pdf) numa linguagem mais simplificada e agradável para jornalistas, profissionais de saúde e a sociedade em geral. A tiragem foi pequena, 4 mil exemplares, porque os pesquisadores não têm recursos nos projetos para essa finalidade. Esse sumário executivo também foi distribuído pelo Ministério da Saúde e enviado com uma carta de agradecimento para todas as 266 maternidades que participaram da pesquisa. Um aspecto interessante desse documento era o item de recomendações para todos os setores envolvidos: gestores, profissionais de saúde (médicos, enfermeiros e outros), universidades formadoras dos profissionais, famílias e também comunicadores sociais. Depois, lançamos outro número temático, numa revista inglesa denominada Reproductive Health 2 e na ocasião do lançamento, já em 2016, fizemos outro sumário executivo da 
mesma forma, com uma linguagem simples, apresentando os principais resultados. Esse foi um mecanismo interessante para aumentar o acesso aos achados da pesquisa e muito bom para os jornalistas fazerem suas matérias, suas pautas sobre o tema. Demos incontáveis entrevistas para jornais, televisão, rádios, blogs etc. Foram muitas mesmo, eu dei quase uma centena... Isso dá um trabalho imenso, que nós, pesquisadores, muitas vezes não temos paciência para fazer.

Marilia Até porque a gente não tem essa formação jornalística.

Duca É uma linguagem diferente da linguagem clínica e científica, é fazer um texto leve, quase literário, para as pessoas lerem. Eu também gosto de fazer isso talvez porque quando era pequena queria ser escritora. Sonhava ser como Rachel de Queiroz, cujas crônicas eu lia na revista O Cruzeiro. Porque para comunicar tem de trabalhar em outra linguagem.

Outra coisa que deu certo nessa divulgação das ideias desses trabalhos foi a realização dos vídeos, dando voz às mulheres que mostraram com o relato das suas experiências que a atenção ao parto era ruim, sofrido e que elas se sentiam abandonadas e sozinhas (https://www.youtube.com/watch? $\mathrm{v}=\mathrm{Qj3Gc3W5iD0}$ e https://www.youtube.com/watch?v=kNZQnYn7PkE). Na segunda pesquisa, o Nascer nas Prisões, mostramos o tratamento dado às grávidas no sistema carcerário e nos hospitais no momento do parto. Nessa segunda vez, os vídeos tiveram mais amadurecimento e o grupo da pesquisa participou mais da edição, que também contou com a expertise da equipe do Fiocruz Vídeo. Esses vídeos foram importantíssimos para divulgar os resultados do estudo. Eles estão disponíveis na Editora Fiocruz e no YouTube (https://www.youtube.com/watch?v=vmi6r-M-KOU).

Luciana E são vídeos que circulam no setor de saúde?

Duca Circulam. O do parto, principalmente, a gente fez para colocar nas salas de espera para as consultas de pré-natal no setor público. Um era sobre o parto vaginal, o outro, sobre a cesariana. Mostrava o que era ruim no parto vaginal, o que não era para ocorrer e ocorria em alguns serviços públicos de saúde e depois mostrava a assistência ao parto em outros serviços que já fazem uma atenção adequada, que gera satisfação para as mulheres. O da cesariana seguia na mesma direção.

Outro aspecto importante na divulgação dos resultados da pesquisa foi a publicação de quatro temas na Radis. A Radis é um espetacular veículo para a divulgação científica dentro e fora do SUS.

Luciana É interessante que chega ao movimento social de uma forma bem capilarizada.

Duca Dos 200 exemplares de CSP que ficaram conosco, 150 enviamos para o movimento social das mulheres que trabalham pela promoção do parto normal, parto humanizado, lá em São Paulo. São várias organizações sociais e, na verdade, foram elas que pediram para distribuir o número temático na área jurídica porque em São Paulo as mulheres entravam com causas na justiça contra a atenção recebida durante o parto e cesariana não desejada sem indicação clínica. O nosso número temático tinha uma revisão atualizada da literatura sobre as recomendações da Organização Mundial da Saúde (OMS) para a atenção ao parto de baixo risco obstétrico. Após alguns meses, esses movimentos sociais entraram com um processo na Procuradoria do Estado de São Paulo contra a Agência Nacional de Saúde Suplementar (ANS), com o argumento da não regulação da cesariana no setor privado pela Agência. Nesse processo solicitavam várias coisas: que ficassem disponíveis e ao acesso das mulheres as taxas de cesariana dos médicos, dos hospitais e das operadoras; que fosse instituída a obrigatoriedade do cartão de pré-natal para as gestantes que utilizavam os serviços de saúde privados; e a obrigatoriedade do preenchimento do partograma para o acompanhamento do trabalho de parto. A ANS respondeu concordando com as solicitações das mulheres. Há muitos anos a ANS vem trabalhando, sem êxito, para reduzir as taxas de cesariana no setor privado. Mas dessa vez foi diferente, foi um processo jurídico contra eles, o que os levou a se movimentarem para obter um resultado mais efetivo. Esse processo coincide com o retorno da Jacqueline Torres para a ANS, depois de fazer o doutorado, sob minha orientação, com os dados do Nascer no Brasil, estudando a experiência de um hospital privado do interior de São Paulo que tinha taxa de cesariana de 50\%, bem abaixo dos valores praticados pelo setor privado, quase $90 \%$. Quando retornou para a ANS, esse processo caiu nas mãos dela e então começou um trabalho interno na Agência para dar uma resposta mais adequada para a solicitação das mulheres. Assim, nasceu o projeto chamado Parto Adequado, que foi uma intervenção multifacetada, em 40 hospitais piloto do setor privado, com o objetivo de reduzir as taxas de cesariana e modificar a atenção ao parto vaginal. A intervenção foi coordenada pela ANS, em parceria com o Hospital Albert Einstein (hospital líder) e o Institute for Healthcare Improvement (IHI), um instituto norte-americano que já trabalha no Brasil há muitos anos, com enfoque na melhoria da qualidade do cuidado. E eles se 
envolveram nesse novo campo da qualidade da atenção ao parto. Nessa época, o Conselho Nacional de Desenvolvimento Científico e Tecnológico (CNPq) e o Departamento de Ciência e Tecnologia (Decit), do Ministério da Saúde e a Fundação Gates abriram uma chamada para financiamento de pesquisa e nós apresentamos um projeto, que tem a coordenação minha e da Jacqueline Torres, para avaliar essa experiência.

Marilia Conta um pouquinho pra gente dos resultados.

Duca O projeto já coletou dados da primeira onda do acompanhamento e verificamos que houve uma redução de $10 \%$ na taxa de cesárea nos hospitais que aderiram ao projeto, no período um ano e meio de intervenção, comparando com o dado destes hospitais no ano anterior à intervenção. A ideia do projeto é avaliar os resultados nesse conjunto de hospitais piloto, para depois, conhecendo as barreiras e facilitadores, expandir os resultados para o resto do sistema.

Além da redução de cesarianas, reduziram também a proporção de bebês nascidos com 37-38 semanas gestacionais. A redução foi também de 10\% e, além disto, houve um aumento expressivo das boas práticas de atenção ao parto e diminuição de intervenções não recomendadas. Faz parte ainda do projeto incorporar a enfermeira obstetra na equipe. Outra coisa interessante é que esses resultados foram muito bem recebidos pelo setor privado, que agora está com 140 hospitais participando dessa inovação.

Marilia Eu lembro que houve uma época em que tentaram colocar um teto na quantidade de cesarianas realizadas e foi um desastre.

Duca Porque não se modifica condutas em instituições de saúde por decreto. A taxa de cesariana baixou porque os hospitais informavam as cesarianas apenas até atingir o teto permitido. E, por vezes, quando acabava a cota, ficava mais restritivo fazer cesarianas e algumas mulheres que necessitavam tinham dificuldade para conseguir.

Luciana Eu quero te perguntar sobre o que vem ocorrendo no SUS.

Duca No SUS foi a Rede Cegonha, um programa que já vem se organizando desde 2011. É um programa que retoma os compromissos, os princípios de garantia do acolhimento das mulheres, com avaliação e classificação de risco, melhoria da qualidade do pré-natal, garantia da vinculação da gestante à maternidade e melhoria da atenção ao parto e nascimento, e acompanhante de livre escolha em todos os momentos da internação para o parto. Além disso, se compromete com a oferta de atenção à saúde das crianças de 0 a 24 meses com qualidade e com o acesso às ações do planejamento reprodutivo. O programa criou uma metodologia de intervenção que contava, dentre outras atividades, com um facilitador, contratado pelo Ministério da Saúde, para trabalhar nas maternidades junto com a equipe local, para processar as mudanças. Também investiu recursos para modificar a ambiência das maternidades: obras para adequar o espaço físico para as mulheres deambularem, comprou poltronas para acompanhantes, leitos PPP (pré-parto, parto e pós-parto), de maneira que a mulher não precise ir ao centro cirúrgico para parir porque o parto não é uma questão cirúrgica. Além disso, buscou criar uma rede de apoio à atenção ao parto, organizando inclusive essa questão da vinculação, da referência, e criou algumas Casas da Gestante que são casas para abrigar mulheres que vêm do interior, que não têm facilidade de acesso, mas têm complicações na gestação. Também para mães que precisavam acompanhar seus filhos que necessitavam de internação em unidade de tratamento intensivo (UTI).

Foi uma pena que poucas dessas casas foram criadas. A ideia era criar uma rede de proteção para que a mulher não peregrinasse, para que o pré-natal melhorasse sua qualidade. Em 2017, nosso grupo, junto à equipe da Universidade Federal do Maranhão, avaliou a Rede Cegonha. Visitamos 640 maternidades do SUS que atendem juntas à metade dos partos do país, e os primeiros resultados mostraram que melhorou a atenção ao parto no sistema público.

Marilia Quais as principais dificuldades para avanços mais substantivos?

Duca Eu acho que ainda há uma grande incompreensão por parte dos médicos, não de todos, sobre as vantagens do parto normal principalmente com a centralidade da mulher na sua condução, em relação à cesariana. A cultura da cesariana como a melhor solução para a mulher foi criada aqui no país e nós vimos que é uma opção conveniente para otimizar o trabalho do obstetra no atendimento ao parto. Então, muitos argumentos são usados para justificar essa escolha, desde os riscos para deslocamentos noturnos dos médicos nas cidades grandes, até o baixo valor pago pelos planos de saúde pela assistência ao parto. Mas os médicos, os obstetras, têm de centrar suas escolhas na melhor evidência científica e, para o parto sem complicação obstétrica, a grande maioria dos partos, a recomendação é o 
vaginal. Mas vejo que estamos num processo de mudança. Muitos jovens obstetras, embora formados em escolas cesaristas, estão optando pelo parto vaginal. Aqui nas maternidades públicas da cidade do Rio de Janeiro uma expressiva parte dos partos é atendida por enfermeiras obstetras. Esse programa no Rio de Janeiro tem aproximadamente 30 anos e mostra o trabalho colaborativo entre médicos e enfermeiros, o que vai moldando uma nova mentalidade de convivência e respeito mútuo entre estes profissionais. Os jovens médicos também se formam num novo contexto da prática clínica, baseada em protocolos, que por sua vez se baseiam em evidências científicas e sabem dos riscos da cesariana para a mulher e para o bebê. Também no setor privado já está acontecendo essa mudança, e esse compartilhamento de espaço da atenção ao parto com os enfermeiros parece uma tendência sem retorno. O enfermeiro obstetra é o profissional de escolha segundo a OMS para a condução da atenção ao parto, por se associar na literatura com os melhores resultados obstétricos. Mas isso está longe ainda de ser equacionado no Brasil.

Marilia Esse modelo da área privada no qual a gestante quer que o médico que faz o pré-natal acompanhe o parto. Fica muito difícil que ele queira fazer algo que não seja uma cesárea marcada. Porque ele tem a agenda dele.

Duca O maior fator de risco que vimos nesse trabalho de avaliação do Parto Adequado para a gestação terminar numa cesariana foi o médico do pré-natal ser o mesmo que entra na maternidade com a mulher durante o seu trabalho de parto. Explicando melhor: no Parto Adequado foram idealizados três modelos de atenção para reduzir cesarianas. No primeiro, o hospital tem equipe para receber as gestantes e fazer o parto, e a equipe que atende ao parto é diferente da que faz o pré-natal; no segundo, o médico que atende no pré-natal é o mesmo que atende ao parto, mas a gestante vai para o hospital ser atendida pela equipe hospitalar e chama o médico do pré-natal somente próximo da hora do parto; no terceiro, o médico do pré-natal poderia ou não ser o mesmo do parto, mas os médicos se organizariam em equipes, todos seriam conhecidos pelas mulheres e para cada dia um deles ficaria na disponibilidade para atender ao parto. Esse último não se instituiu e o médico do pré-natal chegou ao hospital com a gestante. Os dois primeiros modelos tiveram uma taxa de cesariana em torno de $65 \% \mathrm{e}$ o último de $90 \%$. Ou seja, é vantajoso para os resultados desse projeto que pretende reduzir cesariana dissociar o médico do pré-natal do acompanhamento do trabalho de parto, mas não necessariamente do parto em si.

E o terceiro modelo que não se envolveu com as mudanças em curso no hospital, teve o mesmo percentual de cesarianas que vinha sendo praticado antes.

Marilia Claro, não mudou nada. Acho que apresentar as evidências é exatamente como a gente começou a nossa conversa, faz parte da nossa profissão.

Duca Exatamente. Eu apresentei esses resultados para o pessoal do Parto Adequado, grupo que vem se esforçando muito para mudar esse cenário no setor privado. Também estamos vivendo um tempo de mudanças nas mulheres. E esse é o ponto central dessa conversa. As mulheres já não querem cesarianas, estão redescobrindo o parto sob o domínio delas. Essa descoberta não volta atrás, não vai ter retorno, eu acredito. E os serviços de saúde vão acompanhar essa tendência.

Marilia Deixa eu te perguntar agora que a gente está chegando perto do fim, o que te levou ao estudo Nascer nas Prisões?

Duca Pois é, pesquisar o parto e nascimento nas prisões ocorreu por um convite de amigos que trabalham com a saúde prisional, a Alexandra Sánchez e o Bernard Larouzé, que vinham há muito tempo me seduzindo para trabalhar com a questão das mulheres encarceradas. Eu tive medo, não queria me envolver com algo tão pesado e triste. Mas, depois de muito insistir, conseguiram me convencer. Foi o trabalho de pesquisa mais difícil que tivemos, pois o cárcere é fechado com muitas chaves. São muitas barreiras para conseguir entrar e também para realizar a pesquisa. As mulheres vivem em condições muito precárias, em profunda solidão, falta atenção pré-natal, falta todo tipo de cuidado. Elas sofrem muito porque ficam com o bebê no colo durante seis meses e um dia o bebê vai embora. É algo desesperante para elas e, suponho, principalmente para as crianças. Oitenta por cento delas têm outros filhos e quando são presas seus filhos são geralmente repartidos entre familiares, amigos ou mesmo vão para abrigos, desorganizando totalmente a família. Acabamos nos envolvendo muito e o projeto resultou em muitas coisas: na produção de diretrizes de convivência mãe e filho para o DEPEN (Departamento Penitenciário Nacional) e na nossa participação no processo do habeas corpus em favor de todas as mulheres submetidas à prisão provisória para ficarem em prisão domiciliar se 
estiverem na condição de gestantes, puérperas ou de mães de crianças com deficiências e até 12 anos de idade. Nós entramos com o processo pela Abrasco e os dados da pesquisa foram citados no parecer final. Nós ficamos muito emocionados porque tivemos a ousadia de participar disso e o resultado foi favorável para essas mulheres. Esse estudo sobre a maternidade encarcerada era composto de vários subprojetos, tinha a parte de Arquitetura, do Direito, Psicossocial e da Saúde. Essas quatro dimensões deram essa compreensão mais ampla da questão. Além de coordenadora geral, eu coordenei, em particular, o componente da saúde. Fizemos um censo na saúde e os outros componentes foram analisados em quatro presídios. A Luciana Simas, que é uma advogada jovem, muito inteligente, foi quem redigiu essa petição do amicus curiae. Foi ela foi quem escreveu e defendeu no Supremo Tribunal Federal (STF), na linguagem jurídica adequada para sermos escutados. E foi importantíssimo termos entrado, a Abrasco ter nos acolhido... Como falei, fizemos também uma matéria no Radis e os vídeos. Os vídeos estrearam na época do habeas corpus e foi importante para comover a sociedade sobre o sofrimento dessas mulheres. Começou a ser debatido em cineclube, sabia? Vários cineclubes fazendo sessão com o vídeo para discutir o encarceramento de grávidas e a maternidade no cárcere. É emocionante, né?

Marilia Na mesma linha de raciocínio, eu queria que você falasse da questão do aborto. O STF está fazendo uma consulta sobre a legalidade, diga o que você sabe e o que gostaria de fazer.

Duca No próximo Nascer no Brasil o aborto em mulheres hospitalizadas vai ser contemplado pelo estudo. Foi um pedido do Ministério da Saúde, muito bem aceito por nós.

Luciana O misoprostol, é frequente o uso?

Duca Está em uso sim. E diminuiu a complicação do aborto e a mortalidade também, supõe-se que o uso do misoprostol como abortífero seja o motivo da queda nas internações por aborto no SUS.

Nós promovemos um centro de estudos com a perspectiva de pensar o aborto como uma questão de Saúde Pública, que o José Gomes Temporão colocou muito bem quando ele era Ministro da Saúde. No nosso grupo de pesquisa, a Rosa Domingues, em parceria com a Sandra Fonseca da Universidade Federal Fluminense (UFF), está fazendo duas revisões sistemáticas sobre o aborto legal e o aborto inseguro na literatura brasileira. E assim estamos começando os seminários preparatórios para a realização do Nascer no Brasil II. O tema do aborto entrou na nossa pauta e consideramos que se não mudarmos isso não diminuiremos a mortalidade materna, nem o near miss materno que tem alta incidência no Brasil.

Marilia Você tem o dado de quantos abortos inseguros acontecem anualmente no Brasil?

Não, há uma estimativa de que era um terço dos nascimentos. Nós estamos nos preparando com o intuito de participar da consulta pública que será feita à sociedade pelo STF sobre a descriminalização do aborto. E essa vai ser uma batalha muito forte, pesada. Nós nos inscrevemos como Fiocruz para participar, temos alguns dados do Nascer no Brasil sobre a gravidez não pretendida que é muito alta, de $55 \%$ para o conjunto das gestantes no Brasil. É claro que a maior parte das mulheres fica feliz depois com a notícia da gestação, mas encontramos $10 \%$ das puérperas dizendo que não estavam satisfeitas com aquela gestação mesmo depois do bebê ter nascido. Essas, de fato, não queriam ou não podiam ter aquele bebê naquele momento das suas vidas.

Luciana Você é uma mulher corajosa.

Duca Eu já padeci muito, mas não desisto fácil. E espero muito que juntas, nós, mulheres, mudemos o lugar que temos na sociedade brasileira. Contando com a participação dos homens.

1. Nascer no Brasil. Cad Saúde Pública 2014; 30Suppl1. http://www.scielo.br/scielo.php? script $=$ sci_issuetoc $\&$ pid $=0102-311$ X20140013 $\& \operatorname{lng}=\mathrm{pt} \& \mathrm{nrm}=$ iso.
2. Childbirth in Brazil. Report Health 2016; 13Suppl3. https://reproductive-health-journal. biomedcentral.com/articles/supplements/ volume-13-supplement-3. 